\title{
Technical Efficiency and Productivity of Tobacco Control Policies in 16 Selected OECD Countries: A Comparative Study Using Data Envelopment Analysis, 2008-2014
}

Majid Safaei Lari

Tehran University of Medical Sciences

Behzad Raei

Tehran University of Medical Sciences

Pedram Nourizadeh Tehrani

Tehran University of Medical Sciences

Amirhossein Takian ( $\nabla$ takian@tums.ac.ir)

Tehran University of Medical Sciences

\section{Research article}

Keywords: Technical efficiency, Malmquist, DEA, OECD, Tobacco use, Taxation

Posted Date: June 3rd, 2020

DOI: https://doi.org/10.21203/rs.3.rs-31036/v1

License: (c) (i) This work is licensed under a Creative Commons Attribution 4.0 International License. Read Full License 


\section{Abstract}

Background: To date, there is no synthesized evidence about the technical efficiency (TE) of cross-country tobacco control policies. This study aims to measure the efficiency and productivity of tobacco control policies across 16 selected countries of Organization for Economic Co-operation and Development (OECD) from 2008 to 2014.

Method: We used data envelopment analysis (DEA).

MPOWER is an acronym for a WHO proposed package consisting of six tobacco reduction interventions that can be adapted to present a commitment of the parties to a treaty labeled FCTC (Framework Convention on Tobacco Control).

Taxation on tobacco products and pictorial warning labels were chosen as the inputs. Percentage of daily smokers' population above 15 years old and the number of cigarettes used per smoker per day were output variables. Additionally, the Malmquist total factor productivity (TFP) was used to analyze the panel data and measure productivity change and technical efficiency changes over time.

Results: The highest TE score (1.05) was attributed to Norway and the lowest (0.9175) belonged to the United Kingdom (UK). Technological change with a total average of 1.069 would imply that the technology and creativity have increased, while countries have been able to promote their creativity over the time period. Norway with the TFP score of 1.15 was the most productive country, while the UK and Turkey with the TFP scores of 0.95 and .098 respectively, were the least productive countries in the implementation of the MPOWER policies.

Conclusion: Most OECD countries have productively implemented MPOWER policies. Such productive performances are the results of the strong pivotal pictorial warnings. Consequently, the policy of plain packaging seems to hamper the MPOWER policies. Taxation on tobacco products were relatively weak and inefficient.

\section{Background}

With a broad spectrum of adverse health effects, i.e. obstructive pulmonary disease and ischemic heart disease, tobacco use is a serious threat to global public health (1) and a heavy economic and health burden on the societies. As an estimate, five million adults' deaths globally were directly attributed to smoking in 2012 , which is predicted to increase to eight million by $2030(2,3)$. The total smoking-attributable health expenditures were 467 billion USD (United States Dollar) purchasing power parity (PPP) in 2012 (2). Smoking causes death not solely among smokers. Secondhand smoke exposure also has a heavy burden on the society. For instance, in the US, cigarette smoking and secondhand smoke exposure have caused 443,000 premature deaths during 2000-2004 (4). As a main risk factor for non-comunicable diseases (NCDs) (5), smoking may ultimately have significant impact on human development (6). As such, production and use of tobacco products are serious danger to sustainable development through waste of resources and compromising intergenerational equity (7).

Despite noticeable smoking rate reduction among OECD countries, it still remains the widest preventable risk factor for health (8). In 1996, the World Health Organization (WHO) voted to execute the WHO Framework Convention on Tobacco Control (WHO FCTC), and it was adopted in 2003 and finally came into force in 2005 (9-11). So-called MPOWER, in 2008, WHO employed some preventive and control policies aimed at curbing tobacco use. MPOWER has six components: monitoring tobacco use and prevention policies; protecting people from tobacco smoke; offering help to quit tobacco use; warning about the dangers of tobacco; enforcing bans on tobacco advertising, promotion, and sponsorship; and finally raising tobacco taxes (12). Substantial tobacco tax and pictorial warnings are considered as the most cost-effective interventions to reduce tobacco consumption $(12,13)$.

High-income countries (HICs), i.e. OECD countries, usually impose higher taxes on tobacco products such as cigarette, compared with low and middle-income countries (LMICs) (14). Partially due to tax increase, cigarette consumption has pecome less affordable in HICs over time (15). Pictorial warnings on tobacco products is also an effective way to promote Loading [MathJax]/jax/output/CommonHTML/fonts/TeX/fontdata.js 
consumer knowledge about tobacco risks (16). Many smokers from several countries reported to get more awareness about the lethal and adverse risks of smoking from pictorial warning labels than other sources, except for television $(13,17)$. Furthermore, secondhand smokers, especially children, reported a high awareness of warning labels (17). A survey illustrates that smokers who noticed the warnings on cigarette packages were significantly more likely to confirm health risks of tobacco, including lung cancer and heart disease (18).

This study aims to measure the technical efficiency and productivity of tobacco control policies across 16 selected OECD countries over the period of 2008 to 2014 . The cross-country comparisons can provide, we envisage, a useful and practical source of evidence for policy-makers to improve their performance of making palatable policies (19). We used Data Envelopment Analysis (DEA) method to determine the countries' performers (20). To the best of our knowledge, this is the first application of the DEA to measure the efficiency and productivity of preventive medicine policies, comparative efficiency of tobacco control interventions in this article, within a cross-country context.

\section{Method}

1. DEA Analysis and Malmquist Approach

DEA is a non-parametric method to measure relative efficiency (21), which has been frequently used for measuring health system performance (22). As a data-oriented approach, DEA can examine the performance of a set of Decision-Making Units (DMUs) that transform multiple inputs into multiple outputs (23). DEA employs linear programming (LP) methods to calculate the efficiency measures that relative to non-parametric frontiers (20).

There are two versions for DEA: input-oriented and output-oriented. If the aim is to minimize available inputs to provide given levels of outputs, the model would be called input-oriented. On the other hand, if it is assumed that outputs are manageable and the target is to maximize outputs from given levels of inputs, then the model is called output-oriented (20). Pictorial health warnings and taxes on cigarettes have been mentioned in the past as the most effective policies to control tobacco use $(24,25)$. Hence, in order to promote the efficiency, lowering inputs were found out irrational decisions. On the other hand, countries can concentrate on the outputs and improve them by engaging the other tobacco preventive policies (which were quoted in the introduction) from given levels of inputs. Now this can be concluded with regard to definitions of the DEA orientations, an output-oriented version seems to be appropriate for this study (20) as formulated below (21):

$$
\operatorname{Maximizeh}_{0}=\sum_{r=1}^{s} u_{r} y_{r j 0}+u_{0}
$$

Subject to:

$$
\begin{gathered}
\sum_{i=1}^{m} v_{i} x_{i j 0}=1 \\
\sum_{r=1}^{s} u_{r} y_{r j}-\sum v_{i} x_{i j}+u_{0} \leq 0, j=1, \ldots, n \\
u_{r}, v_{i} \geq 0 \\
\leq \\
u_{0}>0
\end{gathered}
$$

Where $\mathrm{y}_{\mathrm{rj}} \mathrm{y}_{\mathrm{rj}}$ is the amount of output $r$ from DMU $j, x_{i j}$ amount of input $i$ to $\mathrm{DMU} j, u_{r}$ weight given to output $r, v_{i}$ weight given to input $i, n$ number of DMUs, $s$ number of outputs, and mnumbers of inputs. The sign of $u_{0}$ shows the reveals returns to

Loading [MathJax]/jax/output/CommonHTML/fonts/TeX/fontdata.js ble returns to scale (VRS or BCC) or constant returns to scale (CRS 
or CCR). Under BCC models, returns to scales can change. If the proportions of increases in both inputs and outputs are the same, the return to scale is constant $\left(u_{0}=0\right)$. And if outputs increase by a larger proportion than each of inputs, the returns to scale would be increasing $\left(u_{0}>0\right)$. Finally, decreasing returns to scale happens when outputs are bigger than inputs by a smaller proportion $\left(u_{0}<0</>\right.$ cript $>$ ). Under CCR model, returns to scale is always constant and doesn't change.

Because efficiency can change over time, the DEA model is appropriate for a specific time period, not over time. This study covers 2008 until 2014, the period when creativity and technology in applying tobacco preventive policies might have changed. Therefore, we used a DEA analysis of panel data across selected countries during the mentioned time period. Consequently, we measured productivity by using DEA-based Malmquist indexes framework (26) and considered a two-input, one-output model. The Malmquist productivity index (MPI) structure is as follow:

$$
M P I=\left[\frac{O E / O G}{O C / O B} * \frac{O F / O G}{O A / O B}\right]^{0.5}
$$

This Malmquist index has been made up by the geometric mean of two different parts. The first expresses that the distance between the two production points, $\mathrm{G}$ and $\mathrm{B}$ (showing a country in the two periods) is measured relative to the production frontier of period 1. The second factor states, this time the distance of these production points $(G$ and $B)$ is measured relative to the production frontier of period 2. The score of the MPI is interpreted as:

1. If the score was greater than unity $(\mathrm{MPI}>1)$, it would indicate the DMU has raised the productivity.

2. If the score was equal to unity $(\mathrm{MPI}=1)$, then it would suggest the productivity is constant.

3. If the score was less than unity $(\mathrm{MPI}<1)$, therefore it would imply that the $\mathrm{DMU}$ in period 2 is less efficient than itself in period 1.

The MPI can be decomposed into two factors: technical change and change in technical efficiency ("catching up"). So according to this decomposition, the MPI will turn into:

$$
M P I=\frac{O E / O G}{O A / O B}\left[\frac{O A}{O C} * \frac{O F}{O E}\right]^{0.5}
$$

The first factor which is outside the brackets shows technical efficiency in both periods and measures efficiency change when transferring from period 1 to period 2 (See Fig. 1). It shows that the DMU will be more efficient (with a score greater than unity) provided it nears to its production frontier; and conversely, if the DMU recedes from its production frontier, it will be less efficient and have less efficiency score (with a score less than unity). Neutrally, if the DMU stays in the same position relative to its frontier and doesn't move, the efficiency will be constant (with a score equal to the unit). The second factor in this MPI (inside the brackets), calculates transfers of the actual frontier between both periods. Shifting in the frontier means a change in technology and creativity of each DMU, which depends in turn on how this DMU functions. The result of each function can be an increase in technology (frontier) with a score greater than the unit, a decrease with a score less than unit, or staying in the same position with a score equal to the unit.

\section{Variables and assumptions}

Out of six MPOWER policies, only two: taxation of tobacco products and pictorial warning labels on tobacco products had numerical datasets, and were included as the inputs in the model (12). The others had mostly been expressed as "Yes" or "No", meaning whether they have executed or not, and their statistical analysis was not conducted. Taxes on most sold brand of cigarettes (taxes as a percent of price) were considered as measures of tobacco taxation. Pictorial warnings are percentages of principal display area mandated to be covered by health warnings (front and back of cigarette packaging). Smokers' prevalence with the measure of smokers' population as a percentage of the population aged greater than 15 years old who are dailv smokers. and also the number of ciaarettes used per smoker per day were variables of the outputs. To Loading [MathJax]/jax/output/CommonHTML/fonts/TeX/fontdata.js 
preserve the positive concept of outputs in the DEA models, and because the efficiency measurement techniques basically suppose that "more outputs are better" (27), the smokers' prevalence and the number of cigarettes used per smoker were conversely entered into the model ( $\left.\frac{1}{\text { outputs }}\right)$.

The Malmquist indexes were calculated under both CRS and VRS, hence no difference which one to be selected (28). Nonetheless, when the study design is cross-national and variables are expressed as ratios, the BCC model is preferable (29). Therefore, we selected the BCC model in this study. We selected the countries and the time period of panel data based on the maximum data availability. Eventually, we chose 16 OECD countries and four point times $(2008,2010,2012$, and 2014$)$. Previous studies recommend that efficiency depends on a number of degrees of freedom, meaning that if the number of DMUs $(\mathrm{n})$ is less than the sum of inputs and outputs $(m+s)$, then most of the DMUs will be likely to be determined as efficient. They introduce a rough rule of thumb in the envelopment model which suggests the number of DMUs ( $n$ ) should be equal to or greater than $\max \{m * s, 3 *(m+s)\}(20)$. To observe this assumption in our study, the rule thumb is equal to $12\{12=3 *(2+2)\}$ which is less than 16 (the number of countries). We used the DEA-SOLVER-LV8 (2014-12-05) application for panel data analysis.

\section{Data}

We gathered the WHO data of the four selected variables for both inputs and outputs, and panel data of pictorial warnings and taxes on cigarette for all 16 countries and for four selected time periods (30). We found no data for pictorial warnings for the year 2008, and used the 2007 data instead. Data for smokers' prevalence and cigarettes used per smoker were taken from OECD Health Database (2017). There were a few missing data points that were properly fixed using a single imputation method.

\section{Results}

A summary of descriptive statistics of all four variables including inputs and outputs has been illustrated in Table 1. The mean of areas covered by pictorial warnings on cigarette packaging has an increase of just .35 percent from 2008 to 2010 , while it remained constant from 2012 to 2014. The main increase was from 2010 to 2012 at 2.66 percent. The mean of taxes on cigarette increased equal to 2.19 percent in the first period and it then experienced slight fluctuations through the other periods. The means of smokers' prevalence and cigarettes used per smoker also decreased over the periods from 2008 to 2014.

Results for the technical efficiency (TE) change or catch-up, technological change (TCH) and MPI for each country are presented in Tables 2, 3 and 4 respectively. Catch-up shows how far each country has transferred from the efficient frontier during the time period. The total average of catch-up with the number of 0.98 would be interpreted that the transfers from the frontier have not been considerable and these selected OECD countries have not been successful in technical efficiency improvement. The technical efficiency has slightly decreased overall. The highest TE score with the value of the 1.05 is attributed to Norway and the lowest with the score of 0.9175 belongs to the United Kingdom. Table 2 shows that all countries except Denmark and the Czech Republic had the technical efficiency scores greater than unity in the first period (20082010); but most of their scores declined during the two next periods. The United States and Denmark showed constant scores that were equal to unity over the three periods. The total mean of standard deviation was just 0.03 , which seems to be really narrow.

Conversely, technological change with a total average of 1.069 would imply that the technology and creativity have risen over the time period, presenting that countries have been able to promote their creativity. Norway and Japan showed the maximum (1.105), and minimum (1.03) scores of technological change mean, respectively. During the first period, all countries apart from Japan, South Korea, and the United States showed technological change scores less than unity. During the second period, the United States and South Korea stayed above unity, while other countries improved their technological

Loading [MathJax]/jax/output/CommonHTML/fonts/TeX/fontdata.js whose technological score fell below unity. Eventually, during the 
third period, all countries showed technological change scores greater than one. The total mean of standard deviation for technological changes was 0.02 , which was not considerably high.

Finally, the MPI value of 1.05 could be recognised as a great deal between technical efficiency changes and technological changes. TFP achievement is a deduction of multiplied TE by TCH. Since this value was greater than unity, it means that productivity grew overall. Individually, only the United Kingdom and Turkey experienced a decrease in their productivity. The maximum TFP with the value of 1.157 was related to Norway, which presented the best performance in engaging inputs and producing outputs. The standard deviation of MPI was calculated 0.04 , which was not significant.

Table 1

Summary of descriptive statistics of variables

\begin{tabular}{|c|c|c|c|c|c|c|}
\hline \multicolumn{3}{|l|}{ Year } & \multirow{2}{*}{$\begin{array}{l}\text { Pictorial health warnings } \\
16\end{array}$} & \multirow{2}{*}{$\begin{array}{l}\text { Taxes } \\
16\end{array}$} & \multirow{2}{*}{$\begin{array}{l}\text { Smokers' prevalence } \\
16\end{array}$} & \multirow{2}{*}{$\begin{array}{l}\text { Cigarettes per smoker per day } \\
16\end{array}$} \\
\hline 2008 & $\mathrm{~N}$ & Valid & & & & \\
\hline & & Missing & 0 & 0 & 0 & 0 \\
\hline & \multicolumn{2}{|c|}{ Mean } & 38.4906 & 70.6194 & 22.2962 & 14.0513 \\
\hline & \multicolumn{2}{|c|}{ Std. Deviation } & 8.93857 & 10.77767 & 3.90097 & 2.38029 \\
\hline & \multicolumn{2}{|c|}{ Minimum } & 30.00 & 36.57 & 14.80 & 8.72 \\
\hline & \multicolumn{2}{|c|}{ Maximum } & 60.00 & 82.83 & 27.90 & 18.80 \\
\hline \multirow[t]{6}{*}{2010} & \multirow[t]{2}{*}{$\mathrm{N}$} & Valid & 16 & 16 & 16 & 16 \\
\hline & & Missing & 0 & 0 & 0 & 0 \\
\hline & \multicolumn{2}{|c|}{ Mean } & 38.8438 & 72.8050 & 21.2144 & 13.4381 \\
\hline & \multicolumn{2}{|c|}{ Std. Deviation } & 8.40975 & 9.96321 & 3.84447 & 1.87056 \\
\hline & \multicolumn{2}{|c|}{ Minimum } & 30.00 & 45.28 & 15.10 & 9.60 \\
\hline & \multicolumn{2}{|c|}{ Maximum } & 60.00 & 82.58 & 29.10 & 16.81 \\
\hline \multirow[t]{6}{*}{2012} & \multirow[t]{2}{*}{$\mathrm{N}$} & Valid & 16 & 16 & 16 & 16 \\
\hline & & Missing & 0 & 0 & 0 & 0 \\
\hline & \multicolumn{2}{|c|}{ Mean } & 41.5000 & 72.5794 & 19.9500 & 13.3150 \\
\hline & \multicolumn{2}{|c|}{ Std. Deviation } & 13.51542 & 9.95557 & 3.50904 & 2.99406 \\
\hline & \multicolumn{2}{|c|}{ Minimum } & 30.00 & 42.93 & 14.20 & 5.94 \\
\hline & \multicolumn{2}{|c|}{ Maximum } & 75.00 & 80.25 & 26.00 & 19.20 \\
\hline \multirow[t]{6}{*}{2014} & \multirow[t]{2}{*}{$\mathrm{N}$} & Valid & 16 & 16 & 16 & 16 \\
\hline & & Missing & 0 & 0 & 0 & 0 \\
\hline & \multicolumn{2}{|c|}{ Mean } & 41.5000 & 72.8938 & 18.9750 & 12.8100 \\
\hline & \multicolumn{2}{|c|}{ Std. Deviation } & 13.51542 & 10.09055 & 4.12205 & 2.58028 \\
\hline & \multicolumn{2}{|c|}{ Minimum } & 30.00 & 42.50 & 12.90 & 6.66 \\
\hline & \multicolumn{2}{|c|}{ Maximum } & 75.00 & 82.20 & 27.30 & 17.60 \\
\hline
\end{tabular}


Table 2

Summary of technical efficiency changes (catch-up)

\begin{tabular}{|lllll|}
\hline Catch-up & $\mathbf{2 0 0 8}=\mathbf{2 0 1 0}$ & $\mathbf{2 0 1 0}=\mathbf{2} \mathbf{2 0 1 2}$ & $\mathbf{2 0 1 2}=\mathbf{2 0 1 4}$ & Average \\
\hline Canada & 1.058899963 & 0.954328508 & 1.021363659 & 1.01153071 \\
\hline Denmark & 1 & 1 & 1 & 1 \\
\hline Czech Republic & 0.990334497 & 0.895927675 & 0.93446017 & 0.940240781 \\
\hline Estonia & 1.03362352 & 0.887236111 & 0.995187992 & 0.972015875 \\
\hline Finland & 1.160814221 & 0.984811557 & 0.936691612 & 1.02743913 \\
\hline France & 1.080234748 & 0.886135757 & 0.944747788 & 0.970372764 \\
\hline Italy & 1.071633118 & 0.91838229 & 0.948864814 & 0.97962674 \\
\hline Japan & 1.000013181 & 0.999992375 & 0.999988693 & 0.999998083 \\
\hline South Korea & 1.000006449 & 1.000001954 & 0.999990607 & 0.99999967 \\
\hline Latvia & 1.021404892 & 1.241569191 & 0.676461035 & 0.979811706 \\
\hline Netherlands & 1.133636089 & 1.007175339 & 0.800041467 & 0.980284298 \\
\hline New Zealand & 1.198386708 & 0.957948978 & 0.93583352 & 1.030723069 \\
\hline Norway & 1.161428958 & 1 & 1 & 1.053809653 \\
\hline Turkey & 1.18449958 & 0.82231349 & 0.835938344 & 0.947583805 \\
\hline United Kingdom & 0.941295973 & 0.910751694 & 0.900635521 & 0.917561063 \\
\hline United States & 1 & 1 & 1 & 1 \\
\hline Average & 1.064763244 & 0.966660932 & 0.933137826 & 0.988187334 \\
\hline Max & 1.198386708 & 1.241569191 & 1.021363659 & 1.053809653 \\
\hline Min & 0.941295973 & 0.82231349 & 0.676461035 & 0.917561063 \\
\hline SD & 0.080097642 & 0.092166206 & 0.09255252 & 0.035099529 \\
\hline
\end{tabular}


Table 3

Summary of technological changes

\begin{tabular}{|lllll|}
\hline Frontier & $\mathbf{2 0 0 8}=\mathbf{>} \mathbf{2 0 1 0}$ & $\mathbf{2 0 1 0}=\mathbf{2 0 1 2}$ & $\mathbf{2 0 1 2}=\mathbf{2 0 1 4}$ & Average \\
\hline Canada & 0.993859483 & 1.059664154 & 1.101568005 & 1.051697 \\
\hline Denmark & 0.929726994 & 1.351507166 & 1.015331575 & 1.098855 \\
\hline Czech Republic & 0.92564388 & 1.122269068 & 1.157120156 & 1.068344 \\
\hline Estonia & 0.967470244 & 1.132966778 & 1.15298826 & 1.084475 \\
\hline Finland & 0.913639341 & 1.1157985 & 1.166117129 & 1.065185 \\
\hline France & 0.941034341 & 1.123378175 & 1.156226727 & 1.073546 \\
\hline Italy & 0.940479721 & 1.123312569 & 1.160758348 & 1.07485 \\
\hline Japan & 1.118028762 & 0.934398536 & 1.056925339 & 1.036451 \\
\hline South Korea & 1.089179898 & 1.050691563 & $1.03913796 *$ & 1.05967 \\
\hline Latvia & 0.981941174 & 1.153601891 & 1.16603115 & 1.100525 \\
\hline Netherlands & 0.979017472 & 1.110662282 & 1.174111281 & 1.08793 \\
\hline New Zealand & 0.98470401 & 1.07497826 & 1.10629314 & 1.055325 \\
\hline Norway & 0.964496049 & 1.123751612 & 1.228423936 & 1.105557 \\
\hline Turkey & 0.960507718 & 1.101780415 & 1.106209432 & 1.056166 \\
\hline United Kingdom & 0.859735249 & 1.123419913 & 1.160609487 & 1.047922 \\
\hline United States & $1.060781312 *$ & $1.027598061 *$ & $1.035893285 *$ & 1.041424 \\
\hline Average & 0.975640353 & 1.108111184 & 1.123984076 & 1.069245 \\
\hline Max & 1.118028762 & 1.351507166 & 1.228423936 & 1.105557 \\
\hline Min & 0.859735249 & 0.934398536 & 1.015331575 & 1.036451 \\
\hline SD & 0.066140988 & 0.084292524 & 0.060568776 & 0.021433 \\
\hline *indicates that infeasible LP problem 0 occurred for computing this number. \\
\hline
\end{tabular}


Table 4

Summary of Malmquist index

\begin{tabular}{|c|c|c|c|c|}
\hline Malmquist & $2008=>2010$ & $2010=>2012$ & $2012=>2014$ & Average \\
\hline Canada & 1.05239777 & 1.01126771 & 1.125101528 & 1.062922 \\
\hline Denmark & 0.929726994 & 1.351507166 & 1.015331575 & 1.098855 \\
\hline Czech Republic & 0.916697066 & 1.005471917 & 1.081282698 & 1.001151 \\
\hline Estonia & 1 & 1.005209038 & 1.147440071 & 1.050883 \\
\hline Finland & 1.06056554 & 1.098851259 & 1.092292133 & 1.083903 \\
\hline France & 1.016537994 & 0.99546557 & 1.092342643 & 1.034782 \\
\hline Italy & 1.007849215 & 1.031630369 & 1.101402754 & 1.046961 \\
\hline Japan & 1.118043498 & 0.934391411 & 1.056913388 & 1.036449 \\
\hline South Korea & 1.089186922 & 1.050693616 & $1.039128199 *$ & 1.05967 \\
\hline Latvia & 1.002959519 & 1.432276566 & 0.788774639 & 1.07467 \\
\hline Netherlands & 1.109849537 & 1.11863166 & 0.939337711 & 1.05594 \\
\hline New Zealand & 1.180056197 & 1.029774326 & 1.035306203 & 1.081712 \\
\hline Norway & 1.120193642 & 1.123751612 & 1.228423936 & 1.157456 \\
\hline Turkey & 1.137720989 & 0.906008898 & 0.924722881 & 0.989484 \\
\hline United Kingdom & $0.809265328 *$ & $1.023156589 *$ & $1.04528613^{*}$ & 0.959236 \\
\hline United States & 1.060781312 & 1.027598061 & 1.035893285 & 1.041424 \\
\hline Average & 1.03823947 & 1.071605361 & 1.046811236 & 1.052219 \\
\hline Max & 1.180056197 & 1.432276566 & 1.228423936 & 1.157456 \\
\hline Min & 0.809265328 & 0.906008898 & 0.788774639 & 0.959236 \\
\hline SD & 0.094904352 & 0.138236682 & 0.100662405 & 0.045971 \\
\hline
\end{tabular}

\section{Discussion}

The WHO's endorsed MPOWER renders effective policy interventions to restrict tobacco consumption. The FCTC parties have committed to implement most of these measures to various extent. This study measured the technical efficiency change, the technological changes and, consequent changes in the productivity of two MPOWER policies, namely tobacco tax raising and pictorial warning, in selected OECD countries, during four time slots from 2008 to 2014.

Our findings indicate that the average TE for the study period slightly reduced, indicating inefficient taxes on tobacco products. The maximum and minimum TE score belonged to Norway and the UK, respectively. Similar to many OECD countries, Norway experienced a regressive trend in daily smoking prevalence, while there was an invariant trend in daily smoking prevalence in the UK that shows the effect of inefficient taxes. Most countries that acquired an increase in the catch-up effect during 2008-10, experienced a decrease in that effect over the next years.

Taxation might have a three-fold effect on tobacco use: a barrier to initiation, lowering consumption among current smokers and nrecludina former smokers from relansina (31) Due to the lack of comprehensive socio-economic data, it is difficult to Loading [MathJax]/jax/output/CommonHTML/fonts/TeX/fontdata.js 
map a clear trend in the effectiveness of the full MPOWER packages among the countries (24). Taxation on tobacco products does not provide nuts-and-bolts consideration for the effectiveness and the mechanisms, through which they exert their effects. Detailed data on different dimensions of tax policy including tax administration and tax structure can inform researchers and strategists to advance related tax policies around the world (32). In addition, the effectiveness of implementing a strategy is mixed and may vary depending on fluctuating circumstances. For example, in countries where access to low, untaxed and inexpensive tobacco products is high, low-income tobacco users show less sensitivity to price changes. Likewise, populations with the higher proportion of younger smokers, especially new starters, might be more sensitive to tax and price policies than that of adult smokers (24). The effect of increased tobacco price on smoking prevalence varies depending on the characteristics of the interest and population within various settings. Heterogeneity in price responsiveness might be explained by factors such as smokers' level of addiction, cigarette affordability, tobacco industry activity to encourage consumers, and product substitution due to availability of a great variety of tobacco products and wide price (33). Factors including tobacco industry price discounting strategies, proactive lobbying and price-reducing marketing in the OECD countries may explain the variance in the effectiveness of MPOWER interventions $(34,35)$. Further, the existence of state-owned tobacco companies imply a complex and ambiguous attitude towards smoking. As long as governments continue to generate significant revenue from monopoly tobacco production, they will face serious inconsistencies in how they deal with the adverse health consequences of tobacco use, e.g. the prevalence of tobacco-related illnesses and mortality (36). This might in turn indicate the need to take strong actions to adapting a range of tactics for appropriate implementation of the WHO's FCTC (37).

According to the WHO estimates, higher taxes, depending on their types, can contribute to almost half of the reduction in smoking. For instance, ad valorem taxes are built upon prices; so, tobacco companies can potentially undermine the effects of higher taxes by reducing supply and putting lower prices on tobacco products. Hence, industry pricing strategies could manipulate consumption levels and change tax revenue. Alternatively, specific excise taxes imposed based on the quantity of products to generate a fixed tax amount must match or outpace periodical inflation to meet their tobacco control objectives (38). Thus, many aspects of each instrument included in the MPOWER package are essential to consider when assessing the merits of designated tools (32).

Our study revealed that all included countries have been following an upward trend towards technological changes, which led to positive performance during 2012-14. Such progress reflects innovations and the use of new technologies, i.e. the implementation of pictorial warning policies. The greatest technology change belonged to Norway, while Japan showed the lowest change. The main elements including the feature of graphic design on cigarette packs, size of the space covered by health warnings, and the time periods for label rotation may account for the impact of pictorial health warnings on smoking prevalence (32). Nevertheless, problems such as the sale of single sticks of cigarettes could reduce the effectiveness of health warnings on the packs.

Another key finding from our study is that the Malmquist index for most countries progressed in the total factor productivity over the study period. Most countries with the Malmquist index over one were those that enjoyed an increasing trend in innovative and technology use. Nevertheless, the observed differences in progress of tobacco control activities among countries might be related to the comprehensiveness of MPOWER package, which might have in turn led to the various extents that a particular country has pursued the FCTC goals.

Norway implemented the point-of-sale tobacco display ban in 2010. This may be the impact of the country's increase in the use of technological changes during 2010-2012, compared to the previous step. Consumers declared that the ban prevented young people to begin smoking and also helped cessation endeavors (39). Norway as the vanguard in this study, also has applied the strongest levels of the monitoring, mass media or anti-tobacco campaigns and smoke free policies. Our unexpected finding was that Turkey and the UK that had the least Malmquist productivity scores, have been implementing much stronger levels of the MPOWER policies (40).

Loading [MathJax]/jax/output/CommonHTML/fonts/TeX/fontdata.js 
The path from policy to reduce tobacco consumption hinges on the possibility that a country will implement tobacco control measures, and on the measures' effectiveness (41). Despite the progress observed in recent years, no government is fully implementing the MPOWER strategy. Many challenges have remained and much more needs to be done to stop one of the worst scourges of modern times. Applying restrictions to all forms of tobacco advertisement, promotion and sponsorship are among the most effective solutions that few countries have adopted with success (42).

Limitations and strengths

Despite its strengths, i.e. being of its first kind to measure efficiency and productivity of MPOWER policies in the OECD countries using robust methods, our assessment was limited. This study provides some insight into the issues associated with tobacco control measures for decision makers and implementers to translate good policy models into tangible action and results. Although comparative productivity is an effective methodology as well as an indicator to partially paint the existing circumstances in any country, the interpretation of such comparisons for a more comprehensive status requires vivid attention to other dimensions. Due to lack of comprehensive data on tobacco-control programs, we confined our analysis to only two outputs. In addition, the data provided by the FCTC parties reflect different methods of data collection, without any adapted standardized survey instruments. This makes direct comparison of prevalence among countries difficult (43). Finally, our findings do not explain the concurrence of other obstacles that may have affected the comprehensive implementation of MPOWER in some countries. Tobacco industry opposition and lobbyists, smuggling, financial barriers like economic benefit of tobacco produce and high cost of cessation programs, might have dwarfed the successful tobacco control plans (42). Socio-economic situations, poverty and lower education are also a major hindrance to access to cessation interventions and acquiring knowledge about the harmful effects of smoking (44). Further studies, which take these variables into account, will need to be undertaken. Nonetheless, this study could generally depict the performance of MPOWER implementation across 16 OECD countries.

\section{Conclusions}

Most OECD countries have productively implemented MPOWER policies to reduce tobacco use. Such productive performances are the results of the strong pivotal pictorial warnings. Consequently, the policy of plain packaging seems to hamper the MPOWER policies. The results of taxes on tobacco products were relatively weak, indicating the need to strengthen the existing policies in this regard. MPOWER interventions were not solely behind the dissatisfying productivity results revealed in this study. To achieve the optimum outcome of the FCTC MPOWER policies and overcome the challenges of smoking use, countries need to tackle the difficult underlying factors, i.e. tobacco industry opposition and lobbyists, smuggling, and low socioeconomic status, which may hinder the meaningful implementation of such policies and undermine sustainable development goals eventually.

\section{Abbreviations}

TE

Technical Efficiency; OECD:Organization for Economic Co-operation and Development; DEA:Data Envelopment Analysis; FCTC:Framework Convention on Tobacco Control; TFP:Total Factor Productivity; UK:United Kingdom; USD:United States Dollar; PPP:Purchasing Power Parity; NCDs:Non-communicable diseases; WHO; World Health Organization; MPOWER:Monitoring tobacco use and prevention policies_Protecting people from tobacco smoke_Offering help to quit tobacco use_Warning about the dangers of tobacco_ Enforcing bans on tobacco advertising, promotion, and sponsorship_ Raising tobacco taxes; HICs:High Income Countries; LMICs; Low and Middle Income Countries; DMUs:Decision Making Units; LP:Linear Programming; VRS:Variable Returns to Scale; CRS:Constant Returns to Scale; MPI:Malmquist Productivity Index; TCH:Technical Change

\section{Declarations}

Loading [MathJax]/jax/output/CommonHTML/fonts/TeX/fontdata.js 


\section{- Ethics approval and consent to participate}

Ethics approval is not required for this paper because our data were not collected from human subjects or/and animals, and all variables used for our study were collected from publically available databases, such as the World Health Organization (https://www.who.int/gho/tobacco/policies/en/,), and OECD Health Database (https://stats.oecd.org/index.aspx? queryid=30127).

\section{- Consent for publication}

Not applicable

\section{- Availability of data and materials}

The datasets generated and/or analysed during the current study are available in the WHO and OECD Health Database repository, https://www.who.int/gho/tobacco/policies/en/, https://stats.oecd.org/index.aspx?queryid=30127

\section{- Competing interests}

The authors declare that they have no competing interests

\section{- Funding}

Not applicable

\section{- Acknowledgements}

Not applicable

\section{References}

1. Drope J, Schluger N, Cahn Z, Drope J, Hamill S, Islami F, Liber A, Nargis N, Stoklosa M. The Tobacco Atlas. Atlanta: American Cancer Society and Vital Strategies; 2018.

2. Goodchild M, Nargis N, d'Espaignet ET. Global economic cost of smoking-attributable diseases. Tobacco control. 2017:tobaccocontrol-2016-053305.

3. Organization WH, Control RfIT. WHO report on the global tobacco epidemic, 2008: the MPOWER package: World Health Organization; 2008.

4. CDC. Smoking-attributable mortality, years of potential life lost, and productivity losses-United States, 2000-2004. MMWR Morb Mortal Wkly Rep. 2008;57(45):1226-8. [PubMed: 19008791].

5. World Health Organization. Four non-communicable diseases, four shared risk factors. Geneva: World Health Organization. Available on line at: http://www.who.int/ncdnet/ about/4diseases/en/index.html.

6. Malone RE, Yang JS. Tobacco: a threat to development?: BMJ Publishing Group Ltd; 2017.

7. Tobacco. and its environmental impact: an overview. Geneva: World Health.

8. Organization; 2017. Licence: CC BY-NC-SA 3.0 IGO.

9. OECD. Health at a Glance 2015: OECD Indicators. Paris: OECD Publishing; 2015.

10. http://dx.doi.org/10.1787/health_glance-2015-en.

11. Organization WH. WHO framework convention on tobacco control. 2003. 
13. Organization WH. WHO report on the global tobacco epidemic, 2013: enforcing bans on tobacco advertising. promotion: World Health Organization; 2013.

14. Organization WH. MPOWER in action: Defeating the global tobacco epidemic. WHO: Geneva, Switzerland.; 2013.

15. FCTC article 11: tobacco warning labels: evidence and recommendations from the ITC project. Waterloo. ON: International Tobacco Control Policy Evaluation Project; 2009 Available from: http://www.itcproject.org [accessed on 13 July 2009].

16. World Health Organization. Appendix IX, tobacco taxes and prices, table 9.1 taxes and retail price for a pack of 20 cigarettes of the most sold brand, 2014. In: WHO report on the global tobacco epidemic, 2015: raising taxes on tobacco. Geneva: World Health Organization; 2015. Available from:

http://www.who.int/entity/tobacco/global_report/2015/table_9_1_taxes_and_prices_most_sold_brand_of_cigarettes.xls? ua $=1$.

17. U.S. National Cancer Institute and World Health Organization. The Economics of Tobacco and Tobacco Control. National Cancer Institute Tobacco Control Monograph.

18. NIH Publication No. 16-CA-8029A

NIH Publication No. 16-CA-8029A. Bethesda MD: U.S. Department of Health and Human Services, National Institutes of Health, National Cancer Institute; and Geneva, CH: World Health Organization; 2016.

19. Fong GT, Hammond D, Hitchman SC. The impact of pictures on the effectiveness of tobacco warnings. Bull World Health Organ. 2009;87:640-3.

20. Hammond D. Tobacco labelling \& packaging toolkit: a guide to FCTC article 11. Waterloo: Tobacco Labelling Resource Centre; 2009.

21. Hammond D, Fong GT, McNeill A, Borland R, Cummings KM. Effectiveness of cigarette warning labels in informing smokers about the risks of smoking: findings from the International Tobacco Control (ITC) Four Country Survey. Tobacco control. 2006;15(suppl 3):iii19-25.

22. Indicators O. Health at a Glance 2011. OECD Indicators OECD, Publishing, Paris DOI: https://doi org/101787/health_glance-2015-en Accessed February. 2015;15:2016.

23. Cooper WW, Seiford LM, Tone K. DATA ENVELOPMENT ANALYSIS A Comprehensive Text with Models, Applications, References and DEA-Solver Software; Second Edition. Springer Science \& Business Media, LLC; 2007.

24. Charnes A, Cooper WW, Rhodes E. Measuring the efficiency of decision making units. Eur J Oper Res. 1978;2(6):429-44.

25. Asandului L, Roman M, Fatulescu P. The efficiency of healthcare systems in Europe: A data envelopment analysis approach. 2013.

26. Cooper WW, Seiford LM, Zhu J. Data envelopment analysis: History, models, and interpretations. Handbook on data envelopment analysis: Springer; 2011. p. 1-39.

27. Chaloupka FJ, Straif K, Leon ME. Effectiveness of tax and price policies in tobacco control. Tob Control. 2011;20(3):235-8.

28. Hammond D. Health warning messages on tobacco products: a review. Tobacco control. 2011;20(5):327-37.

29. Coelli TJ, Rao DSP, O'Donnell CJ, Battese GE. An introduction to efficiency and productivity analysis: Springer Science \& Business Media; 2005.

30. Afonso A, Aubyn M. Non-parametric approaches to education and health efficiency in OECD countries. Journal of Applied Economics. 2005;8:227-46.

31. Coelli T, Rao D, Battese G. An introduction to Efficiency and Productivity Analysis. London: Kluwer Academic Publishers; 1998. p. 49.

32. Hollingsworth B, Smith P. Use of ratios in data envelopment analysis. Appl Econ Lett. 2003;10(11):733-5.

33. WHO. SELECTED TOBACCO CONTROL POLICIES; 2014.

Loading [MathJax]/jax/output/CommonHTML/fonts/TeX/fontdata.js 
34. Jha P, Chaloupka F. Development in practice. Curbing the epidemic: Governments and economics of tobacco control. Washington, DC: The World Bank; 1999: 13-28. 2005.

35. Organization WH. WHO report on the global tobacco epidemic 2019: Offer help to quit tobacco use. 2019.

36. Wilson LM, Avila Tang E, Chander G, Hutton HE, Odelola OA, Elf JL, et al. Impact of tobacco control interventions on smoking initiation, cessation, and prevalence: a systematic review. Journal of environmental and public health. 2012;2012.

37. Gilmore A, Collin J, Townsend J. Transnational tobacco company influence on tax policy during privatization of a state monopoly: British American Tobacco and Uzbekistan. Am J Public Health. 2007;97(11):2001-9.

38. Tauras JA, Peck RM, Chaloupka FJ. The role of retail prices and promotions in determining cigarette brand market shares. Review of industrial Organization. 2006;28(3):253-84.

39. TOBACCO IN IRAN, Euromonitor International. September 2014: Passport.

40. World Health Organization. WHO Report on the Global Tobacco Epidemic 2009: implementing smoke-free environments. Geneva: World Health Organization hwwitm.

41. Meneses FA. Regressive or progressive? the effect of tobacco taxes in Ukraine: World Bank; 2017.

42. Scheffels J, Lavik R. Out of sight, out of mind? Removal of point-of-sale tobacco displays in Norway. Tob Control. 2013;22(e1):e37-42.

43. Organization WH. WHO report on the global tobacco epidemic, 2017: monitoring tobacco use and prevention policies. 2017.

44. Marquez PV, Moreno-Dodson B. Tobacco tax reform at the crossroads of health and development: a multisectoral perspective. World Bank; 2017.

45. Organization WH, Control RfIT. WHO report on the global tobacco epidemic, 2008: the MPOWER package: World Health Organization; 2008.

46. Organization WH. 2012 Global progress report on implementation of the WHO Framework Convention on Tobacco Control. 2012.

47. Siahpush M, McNeill A, Borland R, Fong G. Socioeconomic variations in nicotine dependence, self-efficacy, and intention to quit across four countries: findings from the International Tobacco Control (ITC) Four Country Survey. Tobacco control. 2006;15(suppl 3):iii71-5.

\section{Figures}

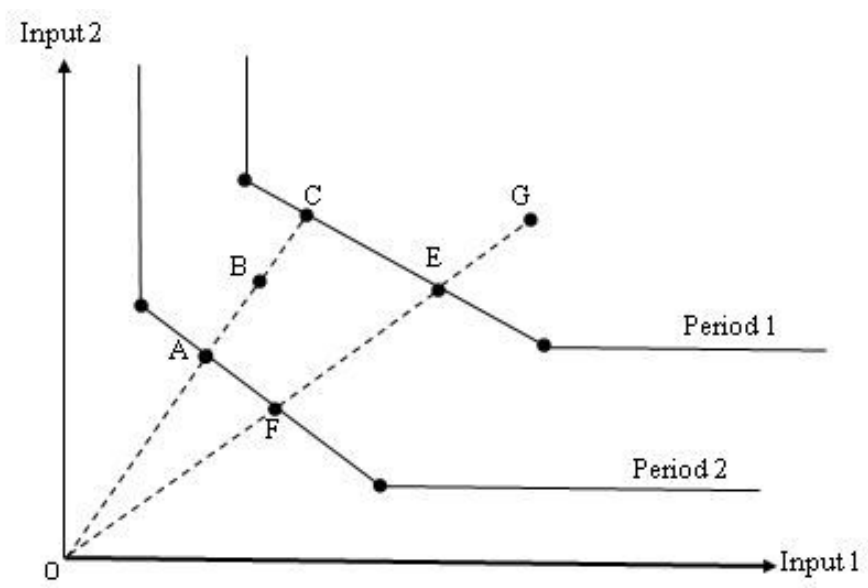

Figure 1

Loading [MathJax]/jax/output/CommonHTML/fonts/TeX/fontdata.js

Page 14/16 
Malmquist Index

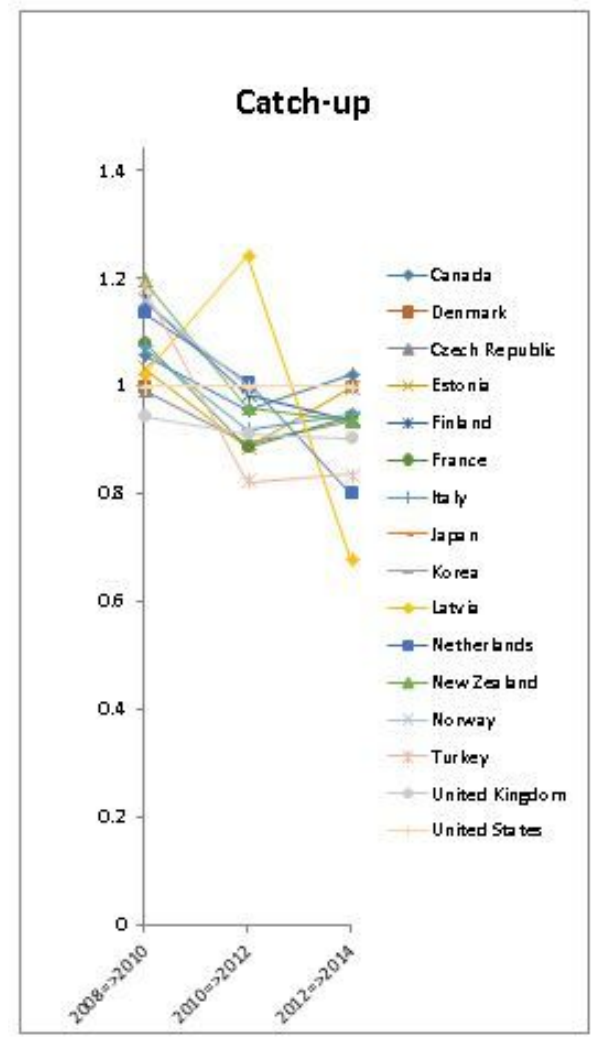

Figure 2

Trend of efficiency changes among DMUs

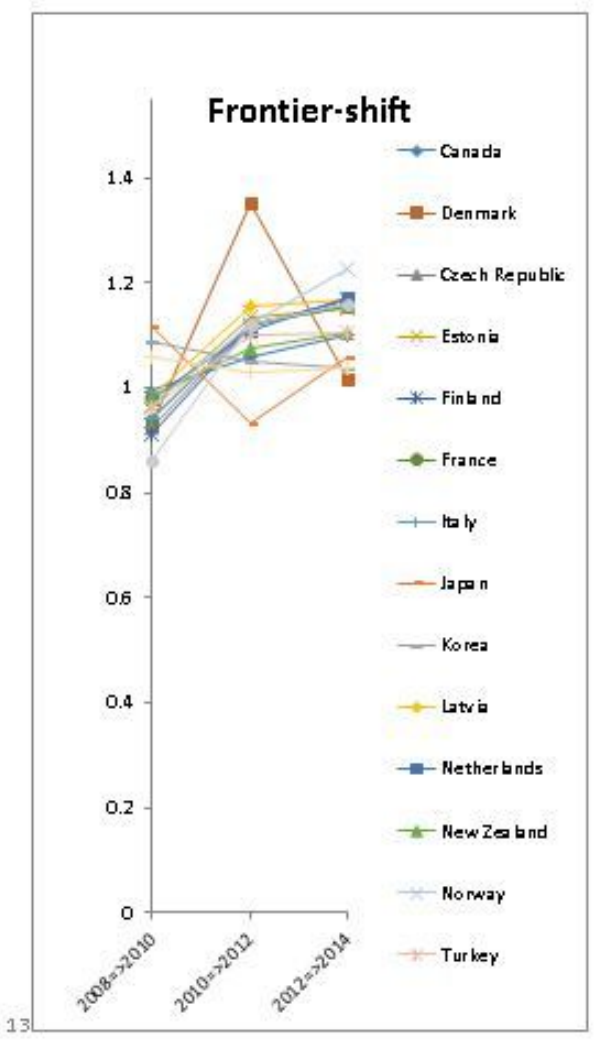

Finure 3

Loading [MathJax]/jax/output/CommonHTML/fonts/TeX/fontdata.js 
Technology changes in DMUs

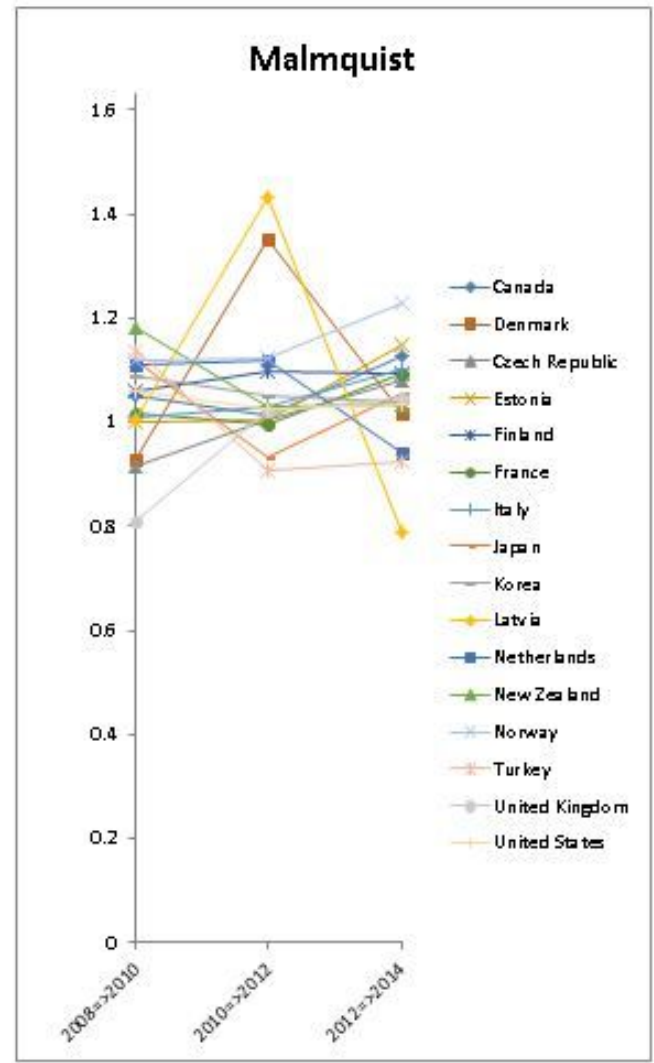

\section{Figure 4}

Productivity changes among DMUs 